\title{
Results of Long-Term Monitoring of the Shelf Water Vertical Thermal Struture at the Black Sea Hydrophysical Polygon of RAS
}

\author{
A. P. Tolstosheev*, S. V. Motyzhev, E. G. Lunev \\ Marine Hydrophysical Institute of RAS, Sevastopol, Russian Federation \\ * tolstosheev@marlin-yug.com
}

Purpose. The geographical and climatic features of the Crimean Southern coast condition significant dynamic activity of the water thermal structure. Studies of the temperature vertical variability in the absence of the tides' dominant affect, permit to specify the upwelling structure and dynamics as well as the characteristics of waves of various origin. Such hardly-forecasted processes, the time scales of which constitute from a few minutes to several days can be revealed and registered only by long-term continuous observations. The aim of the study is to analyze the results of long-term monitoring of the thermal processes in the coastal zone near the Crimean Southern coast. It was performed at the Black Sea hydrophysical scientific polygon.

Methods and Results. In December, 2012 the observation system for operational control of the water temperature vertical distribution was installed at the stationary platform located in the coastal zone of the Black Sea (the Blue Bay) at a distance of $\sim 450 \mathrm{~m}$ from the coast. The sea depth under the platform was $\sim 30 \mathrm{~m}$. Digital temperature sensors having precision better than $0.1^{\circ} \mathrm{C}$ were installed with $1.5 \mathrm{~m}$ intervals in the temperature string of the system. The profiling period was $60 \mathrm{~s}$. The 6.5 year-long experiment with the observation system provided statistically significant and duration-unique serious of data on variability of the thermal processes in the sea coastal region. By early April 2019, the total duration of the system productive functioning was $\sim 900$ days. During this period, more than 1300000 temperature profiles were obtained. Based on the data obtained in 2013, the estimates of a seasonal cycle of the temperature synoptic variability are represented. The upwelling events not related to the wind impact are considered.

Conclusions. The long-term data series resulted from the multi-year experiment permit not only to specify, but also to change some of the existing ideas of the thermal processes' evolution features in shelf zone of the Black Sea. Noted is the expediency of applying the observation system as a segment of the constantly operating network at the coastal polygons for performing hydrophysical measurements in the Black Sea.

Keywords: coastal area, the Black Sea, thermal process, temperature vertical distribution, temperature string, upwelling.

Acknowledgments: the authors are grateful to the reviewers for their valuable remarks and methodical aid. The study is carried out within the framework of the state task on theme "Development of the methods of operational oceanology based on the inter-disciplinary studies of the marine environment formation and evolution processes, and mathematical modeling using the data of remote and direct measurements" at financial and technical support of Marlin-Yug LTD.

For citation: Tolstosheev, A.P., Motyzhev, S.V. and Lunev, E.G., 2020. Results of Long-Term Monitoring of the Shelf Water Vertical Thermal Struture at the Black Sea Hydrophysical Polygon of RAS. Physical Oceanography, [e-journal] 27(1), pp. 69-80. doi:10.22449/1573-160X-2020-1-69-80

DOI: $10.22449 / 1573-160 \mathrm{X}-2020-1-69-80$

(C) A.P. Tolstosheev, S.V. Motyzhev, E.G. Lunev, 2020

(C) Physical Oceanography, 2020

Introduction. Vertical thermal structure of water is one of the most informative parameters when monitoring processes and phenomena that determine the structure and dynamics of marine environment biogeochemical components, the coastal zone state and variability as well as its recreational attractiveness. This article presents some results of an experiment on the study of thermal processes in 
the Black Sea coastal region. In 2012, an autonomous telemetry system for the operational control of water temperature vertical distribution was installed on the oceanographic platform of the Black Sea Hydrophysical Polygon of RAS, located in the southern coast of Crimea. Representative series of vertical temperature profiles obtained by the beginning of 2019 allow us to reconstruct the dynamics of coastal waters in the variability ranges from small-scale to synoptic ones. During the experiment, numerous realizations of upwelling and various types of internal waves were recorded. An extensive bibliography is devoted to the study of internal waves [1-8], however, the mechanisms that generate them, the features of development and dissipation remain poorly studied. Internal waves are hardly predictable and relatively short-term processes, which can be detected and recorded only through systematic long-term observations. The experimental data make it possible to trace in detail the transformation of water temperature vertical profiles related to the propagation of single and wave bores and internal solitons. One of its significant results consists in the fact, that in contrast to previous studies, the data, we obtained during the experiment, was on the thermal variability of coastal waters in the considered region not only in the warm season but also in autumn-winter and winter-spring periods.

Data acquisition and transmission system. In order to establish a systematic operational monitoring of thermal processes in the sea coastal areas, at Marine Hydrophysical Institute (MHI) an autonomous telemetric system for the operational monitoring of water temperature distribution has been developed. The thermal profile line (thermal line) of the system is implemented on the basis of the MicroLAN ${ }^{1}$ network interface. The interface supports the exchange protocol and provides power to all the sensors of the thermal line via one twisted pair bus. As temperature sensors the integrated digital thermometers type $D S 18 B 20^{2}$ (Dallas Semiconductor) were used. After individual calibration of thermometers individually, their error within the range from -2 to $+35^{\circ} \mathrm{C}$ does not exceed $0.1{ }^{\circ} \mathrm{C}$. The thermal line diameter is not more than $13 \mathrm{~mm}$. At the lower anchored end of the thermal line a hydrostatic pressure meter module based on a piezoresistive transducer type MS5535-30C ${ }^{3}$ (Measurement Specialties) is installed. The measurement results are transmitted to the on-board module and broadcast over the air in real time to the coastal receiving station. Each message also contains data on atmospheric pressure, the measurement channel of which is based on a piezoresistive transducer type $M S 5534 C^{4}$ (Measurement Specialties) located in the on-board module. The interval between measurements of all parameters is $60 \mathrm{~s}$.

\footnotetext{
${ }^{1}$ Available at: https://www.maximintegrated.com/en/app-notes/index.mvp/id/155 [Accessed: 20 August 2019].

${ }^{2}$ Available at: https://www.maximintegrated.com/en/products/sensors/DS18B20.html [Accessed: 20 August 2019].

${ }^{3}$ Available at: https://www.amsys.de/downloads/data/MS5535-30C-AMSYS-datasheet.pdf [Accessed: 20 August 2019].

4 Available at:

https://www.te.com/commerce/DocumentDelivery/DDEController?Action=showdoc\&DocId $=$ Data+Sheet\%7FMS5534C\%7FB\%7Fpdf\%7FEnglish\%7FENG_DS_MS5534C_B.pdf\%7FCAT-BLPS0032 [Accessed: 20 August 2019].
} 
At the end of December 2012, the control system was installed on a stationary oceanographic platform of the Black Sea Hydrophysical Polygon. The platform is located on the southern coast of Crimea in the Golubaya Bay at a distance of $\sim 450 \mathrm{~m}$ from the coast at a point with $44^{\circ} 23^{\prime} 38^{\prime \prime} \mathrm{N}, 33^{\circ} 59^{\prime} 15^{\prime \prime}$ E coordinates. Initially, a thermal line with 17 temperature sensors was located on the western side of the platform ( $24 \mathrm{~m}$ depth) and worked until late October 2014. In August 2015, a new thermal line with 19 temperature sensors was installed on the southern (seaward) side of the platform. The depth at the installation place was $\sim 29.5 \mathrm{~m}$.

Similar observations on the Black Sea shelf of the Russian Federation were carried out earlier. Papers [9-12] present the results of studies obtained on the platform of the Black Sea Hydrophysical Polygon, and [13-15] - on an anchored buoy station in the sea coastal zone near Gelendzhik. The observations were carried out mainly in the summer-autumn period, and their duration was limited to several days. During 6.5 years of the experiment with the control system the statistically significant unique in duration series of data on the variability of thermal processes in the sea coastal region were obtained. As of early April 2019, the total time of the system productive work was almost 900 days. During this time more than 1300000 temperature profiles were obtained. The most representative data series were obtained in the following periods: January - February 2013, late June 2013 - January 2014, September 2015 - mid-March 2016, late June 2017 early April 2018, October 2018 - February 2019. Interruptions in operation were mainly due to an outside cover damage or a thermal line break caused by difficult hydrometeorological conditions in the experimental area. The control system provides prompt data delivery to users and can be considered as an observational component of a unified monitoring system for the Black Sea shelf-slope zone [13]. A joint analysis of the experimental results and satellite data will increase the reliability of the results of coastal zone remote monitoring.

Results of seasonal thermal variability observations. As the assessments of thermal variability seasonal cycle we took averaged monthly temperature values interpolated in depth with $1 \mathrm{~m}$ step. As can be seen from the graphs in Fig. 1, $a$ constructed according to 2013 data, in the summer months the layer with the highest temperature variability was expectedly deepened from $12 \mathrm{~m}$ horizon in June to the bottom layer in August. The most intense fluctuations with root-meansquare deviation (RMS) of $5.5{ }^{\circ} \mathrm{C}$ were observed in September in a wide layer at a depth from 10 to $18 \mathrm{~m}$ (Fig. 1, b). The average depths of the pronounced thermocline in June and July were 12 and $17 \mathrm{~m}$, respectively. The obtained results do not contradict the ideas about the transformation of monthly average vertical temperature profiles and make it possible to clarify the features of the seasonal evolution of thermal processes on the Black Sea southern coastal shelf. 

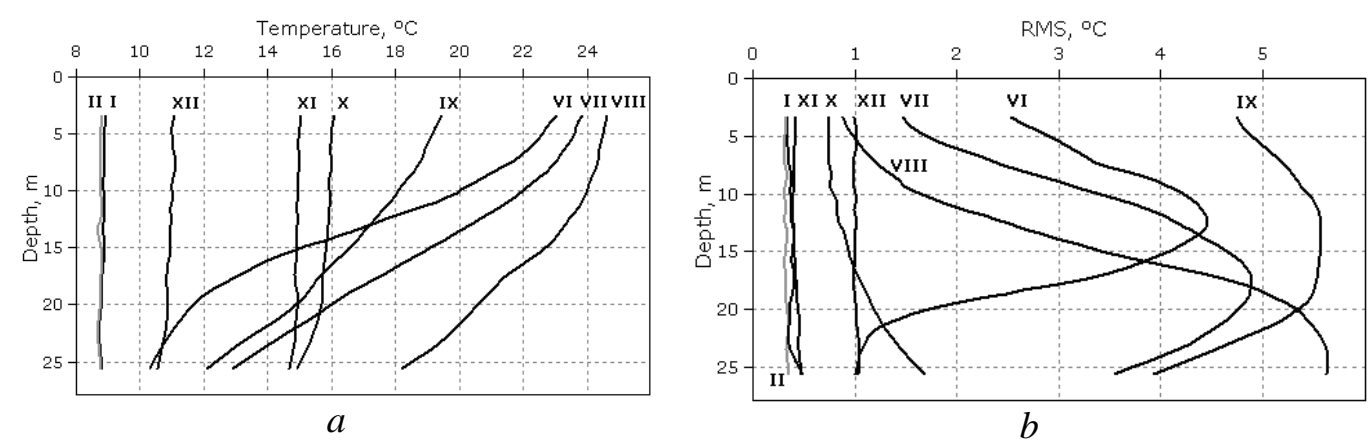

F i g. 1. Monthly average temperature vertical profiles $(a)$ and monthly root-mean square deviations $(b)$ based on the monitoring in 2013. Roman numbers denote the months

The frequency structure of temperature fluctuations was assessed from power spectral densities (PSD), which were calculated by the method of averaging modified periodograms. In Figure 2 the temperature distribution (Fig. 2, a) and temperature PSD in July 2017 at $20 \mathrm{~m}$ depth are represented (Fig. 2, b).
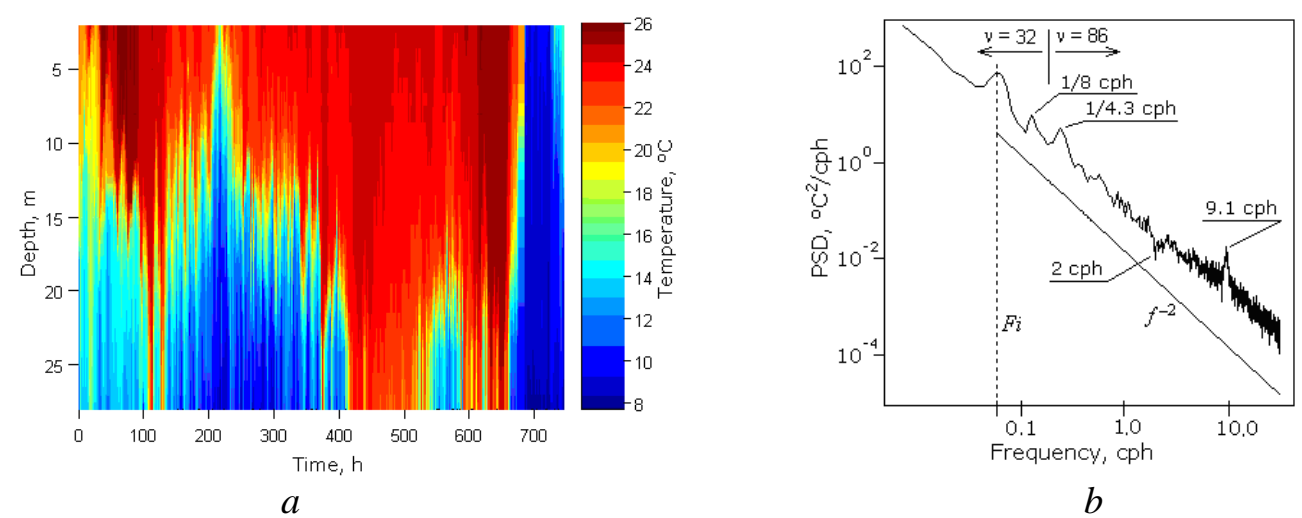

F i g. 2. Temperature distribution $(a)$ and density at the $20 \mathrm{~m}$ depth $(b)$ based on the observation data in July, $2017\left(f^{-2}\right.$ is the canonical spectrum of internal waves; $F_{i}$ is the frequency of inertial oscillations on the platform latitude; 0 hr corresponds to 00:00 on July 1, 2017)

PSD was calculated for different degrees of freedom $v$ : for the resolution of low-frequency mesoscale inhomogeneities $v=32$, for high-frequency ones $v=86$. In Fig. 2, $b$ fluctuation frequencies corresponding to statistically significant energy maxima are given. PSD in the low-frequency area contains three such maxima. The maximum with $F_{i}$ frequency, equal to $1 / 17.07 \mathrm{cph}$, is caused by inertial oscillations, the period of which at the platform latitude is 17.15 hours. In the highfrequency area local minimum PSD are observed in the vicinity of $2 \mathrm{cph}$ frequency and a maximum at $9.1 \mathrm{cph}$ frequency. The slope of the spectrum up to $2 \mathrm{cph}$ frequency coincides well with the canonical spectrum of internal waves. The average buoyancy frequency was assessed by the relation between the density gradient and temperature [16]. At $20 \mathrm{~m}$ depth it was $\sim 18 \mathrm{cph}$. The obtained results differ from the data in [12] with a wider spectral composition in the low-frequency area, since they are based on long-term observational data. 
The results of thermal variability observations at different stages of coastal dynamic processes evolution. During a long-term experiment, representative observational data on the thermal variability of the aquatic environment at various stages of coastal dynamic processes evolution, mainly upwelling, were obtained. Despite the steady scientific and practical interest in such phenomena, their nature remains not fully understood. In any case, the division of the Black Sea coastal upwelling into two species, the Ekman and surge ones, formed respectively under effect of the alongshore wind and the offshore wind, proposed in the monograph [10], seems to be incomplete. An analysis of long-term observation results on the Black Sea southern coastal shelf shows that there is not always a causal relationship between wind parameters and upwelling. As noted in [13], in such radical short-period rearrangements of hydrological structure as, in particular, upwelling, the role played by wind and currents is not completely known. Articles [13,14], which analyze the results of complex experiments in the northeastern Black Sea part are, in our opinion, the most significant publications devoted to clarifying this role. The analysis of hydrometeorological conditions at various stages of upwellings development allowed authors to confirm the existing theory of their wind nature. Along with this, the papers present the results of observations that do not fit into this theory. The solution to the problem can be facilitated by the involvement of systematic long-term observations at the Black Sea Hydrophysical Polygon for analysis. Some of these results are discussed below.

When describing the upwelling, we used the following concepts borrowed from the monograph [10]: upwelling development phase - the interval between the time the surface temperature begins to decrease and the time the surface temperature reaches its lowest value; intensity - the temperature difference of the surface layer at the beginning and in the end of the development phase; variation rate of the surface layer temperature during the development period; upwelling duration - the interval between the time the surface layer temperature begins to decrease and the time when the surface layer temperature reaches its maximum value. Data on wind characteristics are available on the website http://dvs.net.ru/mp/data/main_ru.shtml\#model of MHI RAS.

Before full upwelling on June 22-23, 2013 (Fig. 3), a stable northwestern wind of 4-6 m/s and a two-layer hydrological structure with a thermocline depth of 10-13 m were observed. Upwelling began to develop around 07:00 on June 22 from a temperature decrease in the layer below $8 \mathrm{~m}$. After 6 hours the near-surface layer temperature began to decrease noticeably. From 13:15 on June 22 to $03: 20$ on June 23 , the temperature at $2 \mathrm{~m}$ depth changed from 22.9 to $11.9^{\circ} \mathrm{C}$. The average upwelling development rate was $\sim 0.8^{\circ} \mathrm{C} / \mathrm{h}$, and its intensity was $11^{\circ} \mathrm{C}$. The largest vertical gradient in the development phase was recorded on June 22 at 15:54 at $4 \mathrm{~m}$ depth and amounted to $5.1^{\circ} \mathrm{C} / \mathrm{m}$. Relatively stable upwelling phase lasted for $\sim 2.5$ hours. Starting at 06:40 on June 23, the temperature began to rise. Within $1 \mathrm{~h} 40$ min the surface layer temperature changed from 12.4 to $21.7^{\circ} \mathrm{C}$. The temperature variation rate was $\sim 5.8^{\circ} \mathrm{C} / \mathrm{h}$. The temperature profile measurements with $1 \mathrm{~min}$ interval provided the detailing of heating process. The upwelling relaxation was caused by the invasion of a stream of warm water masses with a steep front localized in the upper layer to $\sim 12 \mathrm{~m}$ depth. Within 2 minutes, from 07:06 to 07:08, 
the temperature at $5 \mathrm{~m}$ depth of the frontal zone changed from 12.1 to $14.9{ }^{\circ} \mathrm{C}$ $\left(\sim 1.4{ }^{\circ} \mathrm{C} / \mathrm{min}\right)$. By $08: 15$ on June 23 , the temperature at $2 \mathrm{~m}$ depth reached $21.7^{\circ} \mathrm{C}$ and the upwelling ended. Its duration was $\sim 25$ hours. Approximately 1.5 days after the end of the upwelling, a stable two-layer thermal stratification of waters with the upper quasi-mixed layer thickness of $9 \mathrm{~m}$ and a temperature gradient in the thermocline of $10.7^{\circ} \mathrm{C} / \mathrm{m}$ was formed in the area under study.

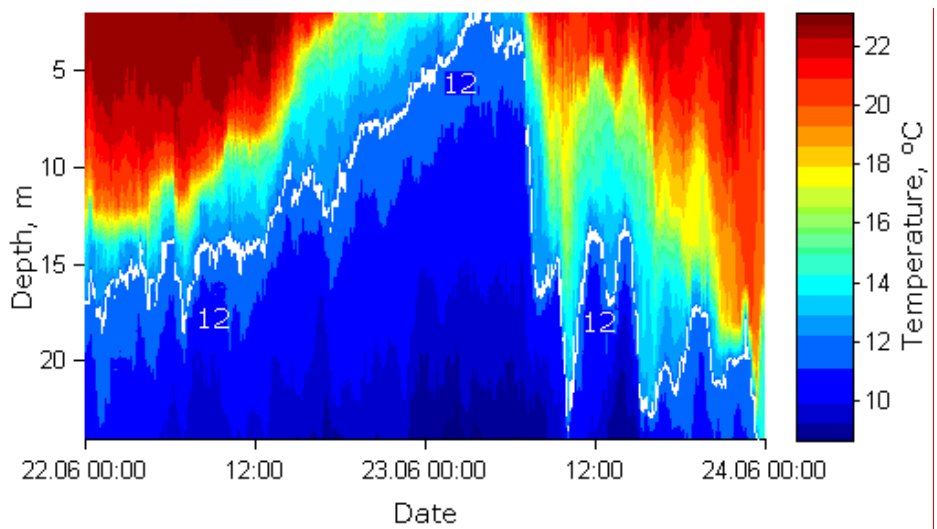

F i g. 3. Temperature distribution and isotherm $12{ }^{\circ} \mathrm{C}$ (white line) in the full upwelling in June 22-23, 2013
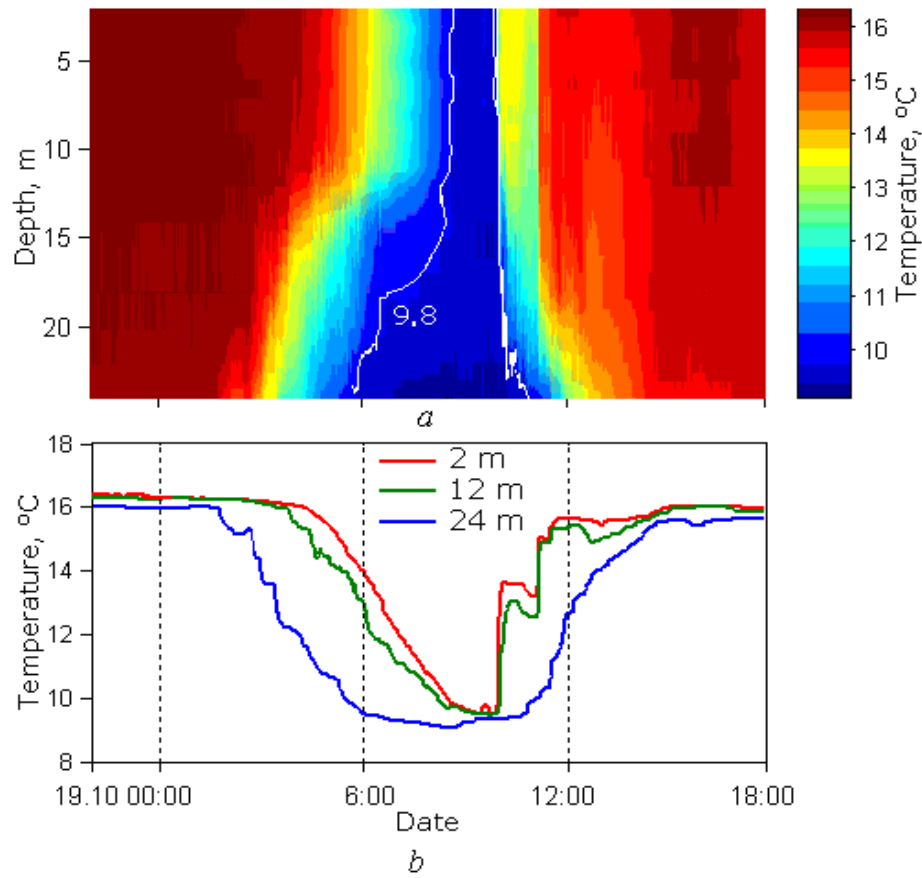

F i g. 4. Temperature distribution and isotherm $9.8^{\circ} \mathrm{C}$ (white line) in the full upwelling on October 19, $2013(a)$; temperature time series on horizons 2,12 and $24 \mathrm{~m}($ b) 
Before the beginning of full upwelling on October 19, 2013, a hydrological structure, quasi-isothermal throughout its depth, with $(16 \pm 0.2){ }^{\circ} \mathrm{C}$ temperature and a weak southern wind were observed. The temperature distribution in various upwelling phases is shown in Fig. 4, a. Immediately before the upwelling, the wind velocity increased to $12 \mathrm{~m} / \mathrm{s}$ and its direction changed to the northern one. The upwelling development began at 01:48 on October 19 from the bottom layers. By 03:00 a cold water front reached the upper layer with phase delays approximately the same for all observation horizons. By 09:30, the temperature at all horizons had decreased to the minimum values $(9.4 \pm 0.1)^{\circ} \mathrm{C}$. A steady low temperature regime was observed for 30 minutes. During the formation of the leading upwelling front, the largest temperature gradient was observed at $12 \mathrm{~m}$ horizon and amounted to $\sim 3{ }^{\circ} \mathrm{C} / \mathrm{h}$. At 10:00 a sharp increase in temperature began in the layer from $12 \mathrm{~m}$ to the surface (Fig. 4, b). At the same time, the wind parameters did not vary significantly. Upwelling relaxation took place at a high rate. Within 3 minutes, from 10:05 to 10:08, the temperature at $5 \mathrm{~m}$ horizon changed from 9.8 to $13.4{ }^{\circ} \mathrm{C}\left(\sim 3{ }^{\circ} \mathrm{C} / \mathrm{min}\right)$. The formation of the upwelling trailing edge is well traced by the behavior of $9.8^{\circ} \mathrm{C}$ isotherm (Fig. 4, a), which has shifted from the surface to the bottom layer within $50 \mathrm{~min}$.

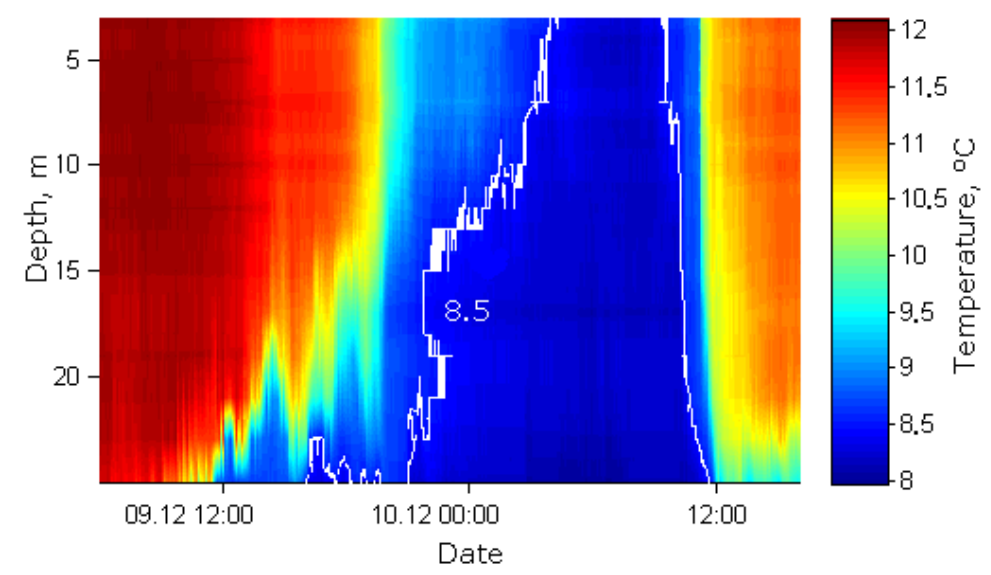

F i g. 5. Temperature distribution and isotherm $8.5^{\circ} \mathrm{C}$ (white line) in the full upwelling on December 9-10, 2013

As in the previous case, before the full upwelling on December 9-10, 2013 (Fig. 5) a hydrological structure, quasi-isothermal over the entire depth, with $(11,8 \pm 0,2){ }^{\circ} \mathrm{C}$ temperature and a north-western wind, the velocity of which did not exceed $6 \mathrm{~m} / \mathrm{s}$, were observed. In the morning of December 9, the wind direction changed to south-western, its velocity reached $12 \mathrm{~m} / \mathrm{s}$ and from 06:30 cold water began to flow into the bottom layers. At 09:00 at the surface layer temperature of $12.1^{\circ} \mathrm{C}$ the development phase of full upwelling began, at the end of which at 05:30 on December 10 the surface layer temperature dropped to $8.3{ }^{\circ} \mathrm{C}$. Relatively stable phase lasted for $\sim 3.5$ hours. Around 09:00 on December 10, with a relatively slow increase in temperature at the horizons above $10 \mathrm{~m}$, the upwelling relaxation began. At 11:09, the relaxation rate increased sharply: within 3 minutes the temperature of layer above $5 \mathrm{~m}$ increased by $\sim{ }^{\circ} \mathrm{C}$. The upwelling ended by 
13:00, its duration was 28 hours. After the upwelling development phase ended and until it was completely relaxed, a northern stable wind of $10 \mathrm{~m} / \mathrm{s}$ velocity was observed.

Before the full upwelling on July 28 - August 6,2017 and during the process of its development a weak wind of variable directions was observed. In Fig. 6 the temperature distribution before upwelling and during the phase of its development is represented. Upwelling was preceded by a downwelling with $(25 \pm 0.3){ }^{\circ} \mathrm{C}$ temperatures. Just prior to upwelling, low-temperature water clusters began to flow into the bottom layer. The fronts of the clusters are clearly visible in Fig. 6. The upwelling development phase began on July 28 at 10:20 and ended on July 29 at 20:50. During this period, an increase in the south-western wind was observed, its velocity reached $12 \mathrm{~m} / \mathrm{s}$. The temperature in the near-surface layer decreased from 25.2 to $9.2{ }^{\circ} \mathrm{C}$. The average rate of temperature variation was $\sim 0.5^{\circ} \mathrm{C} / \mathrm{h}$ and the upwelling intensity was $16^{\circ} \mathrm{C}$. The largest vertical gradient in the development phase was recorded on July 28 at 11:41 at $21 \mathrm{~m}$ depth and amounted to $3.4^{\circ} \mathrm{C} / \mathrm{m}$.

The upwelling relaxation began at 02:00 on July 31 with temperature increase in the sea upper layer. In the first half of the day on August 2, a strong northeastern wind blew at $12 \mathrm{~m} / \mathrm{s}$ velocity, causing drift transport and, as a result, a sharp increase in the water temperature in the bottom layer occured. By 11:00 on August 5, the surface layer temperature reached $25{ }^{\circ} \mathrm{C}$ and the upwelling ended. Its duration was $\sim 8$ days.

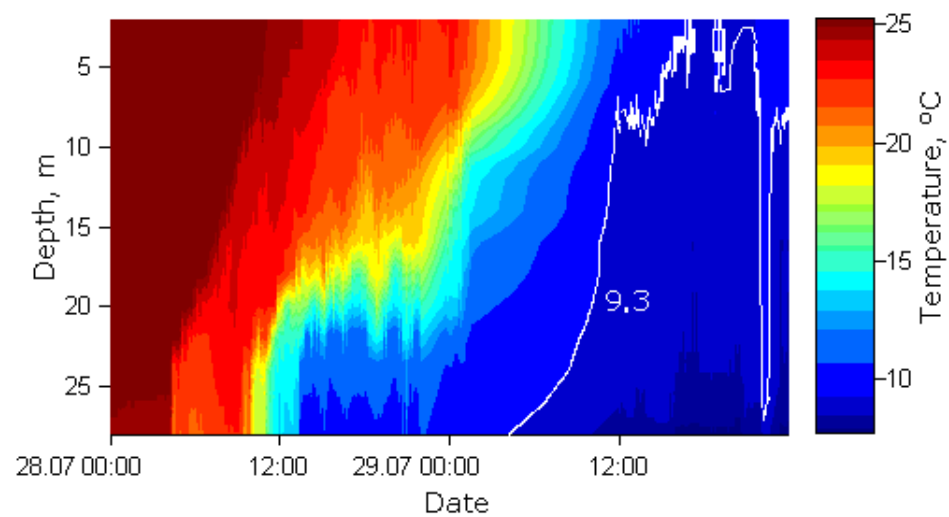

F i g. 6. Temperature distribution and isotherm $9.3{ }^{\circ} \mathrm{C}$ (white line) during the development phase of upwelling on July 28 - August 06, 2017

During the experiment the numerous realizations of nonlinear internal waves single and wave bores, internal solitons - were also observed. Descriptions of such processes in the literature are relatively rare, since systematic long-term measurements with high temporal resolution are required for studying their dynamics [17]. In the area where the experiment was carried out the bores were observed earlier, however, these observations are few in number and were carried out mainly in the summer periods $[1,6]$. In the experiment under consideration the long-term observations provided the registration of dozens of bore implementations in different seasons of the year. In Fig. 7 an example of a single benthic bore recorded on October 18, 2014 is given. Before the start of bore, a quasi-isothermal vertical water 
structure (Fig. 7, b) and a weak wind were observed. In the morning of October 18, the northern wind sharply intensified, its velocity reached $15 \mathrm{~m} / \mathrm{s}$. Within $1 \mathrm{~h}$ the temperature in the bottom layer decreased from 18.6 to $9.9{ }^{\circ} \mathrm{C}$. The formed bottom thermocline (Fig. 7, c) persisted for $3 \mathrm{~h}$, after which the stratification weakening began. By 20:30 (Fig. 7, d) the hydrometeorological conditions that preceded the bore were set.

As already mentioned, in the works devoted to the analysis of thermal processes on the Southern coast of Crimea shelf, mainly the results of observations in the summer seasons were used. In the experiment under consideration representative series of data were also obtained in the autumn-winter and winterspring periods. Although the results of the analysis of some of these data were considered above, we give here as an example of thermal activity in the cold season the monitoring data obtained in November 2015. Figure 8 shows a fragment of time series of temperature profiles from November 10 to 18 . Three full upwellings were recorded during this period. The first upwelling lasted from 23:40 on November 10 to 19:00 on November 11, the second - from 05:00 to 18:30 on November 13, the third - from 14:00 on November 16 to 03:00 on November 17. Upwellings were formed under conditions of the western wind sharp intensifications up to $15 \mathrm{~m} / \mathrm{s}$. After each upwelling the trains of nonlinear internal waves were observed.

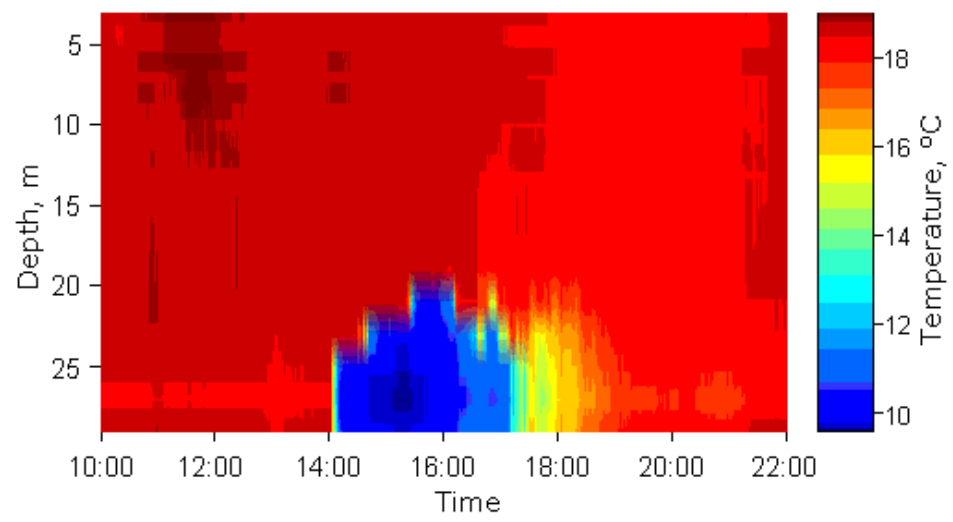

$a$

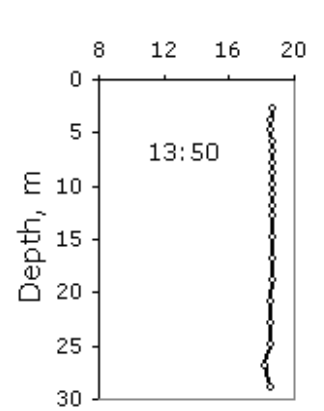

$b$
Temperature, ${ }^{\circ} \mathrm{C}$

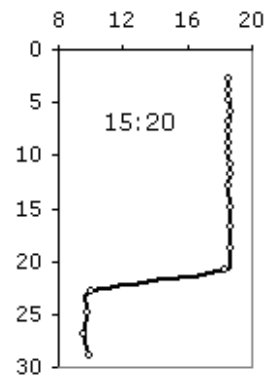

$c$

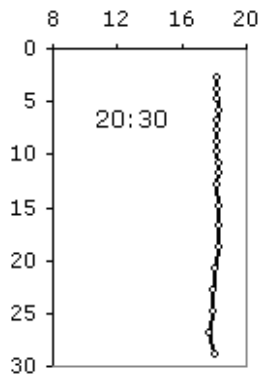

$d$

F i g. 7. Temperature distribution at passing of the near-bottom solitary internal wave on October 18, $2014(a)$ and the temperature profiles before $(b)$, during $(c)$ and after $(d)$ its passing 


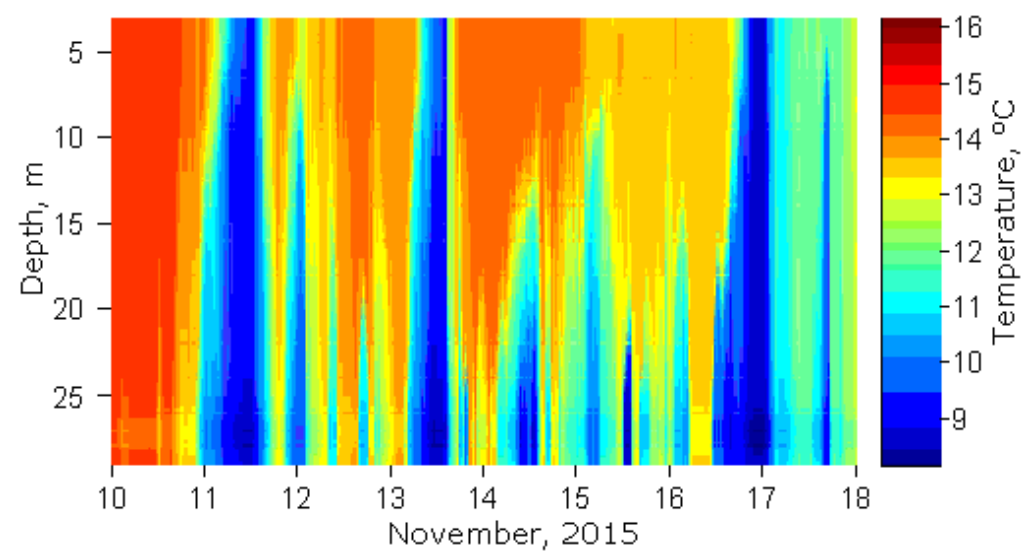

F i g. 8. Full upwellings in November, 2015

Conclusions. Over 6.5 years of observations at the Black Sea Hydrophysical Polygon of RAS, located in the Southern coast of Crimea, long-term series of systematic data on the water vertical thermal structure have been obtained. Yearround observations were carried out with high spatial-temporal resolution, and their results not only clarify but also change some of the existing ideas about the features of thermal processes evolution in the Black Sea shelf zone. In contrast to previous observations performed in this region, the representative data on the water temperature variability in cold periods of the year were obtained in this experiment. The considered realizations of thermal phenomena constitute only an insignificant part of the obtained materials. Their more detailed analysis requires the use of a complex of hydrometeorological parameters and is beyond the scope of this paper. The experiment results allow us to justifiably suggest the possibility and expediency of using the observation system as a segment of a constantly operating network of coastal test sites for hydrophysical measurements in the Black Sea.

\section{REFERENCES}

1. Lisichenok, A.D., 2005. Intensive Internal Waves in the Black Sea. In: MHI, 2005. Ecological Safety of Coastal and Shelf Zones and Comprehensive Use of Shelf Resources. Sevastopol, MHI. Iss. 12, pp. 49-59 (in Russian).

2. Liapidevskii, V.Y., Novotryasov, V.V., Khrapchenkov, F.F. and Yaroshchuk, I.O., 2017. Internal Wave Bore in the Shelf Zone of the Sea. Journal of Applied Mechanics and Technical Physics, 58(5), pp. 809-818. https://doi.org/10.1134/S0021894417050066

3. Ivanov, V.A., Shul'ga, T.Ya., Bagaev, A.V., Medvedeva, A.V., Plastun, T.V., Verzhevskaya, L.V. and Svishcheva, I.A., 2019. Internal Waves on the Black Sea Shelf Near the Heracles Peninsula: Modeling and Observation. Physical Oceanography, 26(4), pp. 288-303. doi:10.22449/1573-160X-2019-4-288-304

4. Pritchard, M. and Weller, R.A., 2005. Observations of Internal Bores and Waves of Elevation on the New England Inner Continental Shelf During Summer 2001. Journal of Geophysical Research, 110(C3), C03020. doi:10.1029/2004JC002377 
5. Badiey, M., Wan, L. and Song, A., 2013. Three-Dimensional Mapping of Evolving Internal Waves During the Shallow Water 2006 Experiment. The Journal of the Acoustical Society of America, 134(1), EL7, pp. EL7-EL13. doi:10.1121/1.4804945

6. Serebryany, A., 2014. Internal Waves on a Shelf. Hydroacoustics, 17(1), pp. 187198. Available at: http://yadda.icm.edu.pl/yadda/element/bwmeta1.element.baztechb5a36445-3bb4-4a8e-ad13-d196625518e9/c/Serebryany.pdf [Accessed: 15 January 2020].

7. Walter, R.K., Stastna, M., Woodson, C.B. and Monismith, S.G., 2016. Observations of Nonlinear Internal Waves at a Persistent Coastal Upwelling Front. Continental Shelf Research, 117, pp. 100-117. doi:10.1016/j.csr.2016.02.007

8. Colosi, J.A., Kumar, N., Suanda, S.H., Freismuth, T.M. and MacMahan, J.H., 2018. Statistics of Internal Tide Bores and Internal Solitary Waves Observed on the Inner Continental Shelf off Point Sal, California. Journal of Physical Oceanography, 48(1), pp. 123-143. doi:10.1175/JPO-D-17-0045.1

9. Ivanov, V.A. and Serebryany, A.N., 1985. Short-period Internal Waves in the Coastal Zone of a Nontidal Sea. Izvestiya. Atmospheric and Oceanic Physics, 21(6), pp. 496-501.

10. Blatov, A.S. and Ivanov, V.A., 1992. [Hydrology and Hydrodynamics of the Black Sea Shelf Zone (on the Example of the South Coast of Crimea]. Kiev: Naukova Dumka, 244 p. (in Russian).

11. Serebryany, A.N. and Ivanov, V.A., 2013. Study of Internal Waves in the Black Sea from Oceanographic Platform of Marine Geophysical Institute. Fundamentalnaya i Prikladnaya Gidrofizika, 6(3), pp. 34-45 (in Russian).

12. Serebryany, A.N., Ivanov, V.A., Kuznetsov, A.S., Khimchenko, E.E., Lavrova, O.Y. and Simonova, Y.V., 2014. [Studies of Internal Waves and Currents in the Black Sea from the Platform of the Marine Hydrophysical Institute in the Summer 2014]. In: MHI, 2014. Ecological Safety of Coastal and Shelf Zones and Comprehensive Use of Shelf Resources. Sevastopol, MHI. Iss. 28, pp. 62-70 (in Russian).

13. Zatsepin, A.G., Silvestrova, K.P., Kuklev, S.B., Piotoukh, V.B. and Podymov, O.I., 2016. Observations of a Cycle of Intense Coastal Upwelling and Downwelling at the Research Site of the Shirshov Institute of Oceanology in the Black Sea. Oceanology, 56(2), pp. 188-199. doi:10.1134/S0001437016020211

14. Silvestrova, K.P., Zatsepin, A.G. and Myslenkov, S.A., 2017. Coastal Upwelling in the Gelendzhik Area of the Black Sea: Effect of Wind and Dynamics. Oceanology, 57(4), pp. 469-477. doi:10.1134/S0001437017040178

15. Ocherednik, V.V. and Zapevalov, A.S., 2018. Investigation of the Short-Period Variability of the Temperature Field on the Black Sea Hydrophysical Training Ground of the Institute of Oceanology RAS. Ecological Safety of Coastal and Shelf Zones of Sea, (1), pp. 44-49. doi:10.22449/2413-5577-2018-1-44-49 (in Russian).

16. Van Haren, H., Groenwegen, R., Laan, M. and Koster, B., 2001. A Fast and Accurate Thermistor String. Journal of Atmospheric and Oceanic Technology, 18(2), pp. 256-265. https://doi.org/10.1175/1520-0426(2001)018<0256:AFAATS >2.0.CO;2

17. Nam, S. and Send, U., 2011. Direct Evidence of Deep Water Intrusions onto the Continental Shelf via Surging Internal Tides. Journal of Geophysical Research: Oceans, 116(C5), C05004. doi:10.1029/2010JC006692 
About the authors:

Aleksey P. Tolstosheev, Senior Research Associate, Marine Hydrophysical Institute of RAS (2 Kapitanskaya Str., Sevastopol, 299011, Russian Federation), Ph. D. (Tech.), ORCID ID: 0000-00020771-0879, ResearcherID: G-1901-2014, Scopus Author ID: 56828803500, tolstosheev@marlinyug.com

Sergey V. Motyzhev, Head of the Scientific Direction of Instrumentation, Marine Hydrophysical Institute of RAS (2 Kapitanskaya Str., Sevastopol, 299011, Russian Federation), Dr. Sci. (Tech.), ORCID ID: 0000-0002-8438-2602, Scopus Author ID: 65073545040, motyzhev@marlin-yug.com

Evgeniy G. Lunev, Research Associate, Marine Hydrophysical Institute of RAS (2 Kapitanskaya Str., Sevastopol, 299011, Russian Federation), Ph.D. (Tech.), ORCID ID: 00000002-7138-3024, Scopus Author ID: 23994266100, lunev@ marlin-yug.com

Contribution of the co-authors:

Aleksey P. Tolstosheev - carrying out the experimental studies, analysis of materials, writing and updating the paper text, discussion of the results, formulation of conclusions

Sergey V. Motyzhev - problem statement, updating the paper text, discussion of the results, formulation of conclusions

Evgeniy G. Lunev - carrying out the experimental studies, updating the paper text, discussion of the results, formulation of conclusions

All the authors have read and approved the final manuscript.

The authors declare that they have no conflict of interest. 